\title{
PERAN KEPALA SEKOLAH DAN TIM PENJAMIN MUTU SEKOLAH DALAM MENERAPKAN MANAJEMEN MUTU DI SDN 1 LEJANG KABUPATEN PANGKEP
}

\author{
${ }^{1 *}$ Kamaruddin, ${ }^{2}$ Muh Yahya, ${ }^{3}$ Andi Mulyadi, ${ }^{4}$ Sigit Bin Basso \\ ${ }^{1}$ UPT SDN 1 Lejang, Pangkep, Indonesia \\ ${ }^{2}$ STKIP-PI, Makassar, Indonesia \\ ${ }^{3}$ STKIP-PI, Makassar, Indonesia \\ ${ }^{4}$ Mahasiswa STKIP-PI, Makassar, Indonesia
}

*Email Korespondensi: kamaruddinmajid195@gmail.com

\section{INFO ARTIKEL}

Diterima 11 September 2021 Direvisi 16 Oktober 2021 Dipublikasikan 31 Desember 2021

\begin{abstract}
A B S T R A K
Penelitian bertujuan mendeskripsikan 1) Kondisi mutu Pendidikan, 2) Langkahlangkah penerapan manajemen, 3) Peran kepala sekolah Tim Penjaminan Mutu dalam menerapkan manajemen di SDN 1 Lejang Kabupaten Pangkep. Jenis penelitian Deskriptif Kualitatif. Desain penelitian Fenomonologi. Teknik pengumpulan Data melalui Observasi, Wawancara, Dokumentasi. Teknik analisis data mengunakan Reduksi data, Penyajian data, Penarikan kesimpulan. Hasil penelitian menunjukan bahwa 1) Kondisi Mutu Pendidikan yakni sudah bagus, tapi sarana dan prasarana masih kurang, 2) Langkah-lagkah penerapan manajemen yakni penetapan mutu, pemetaan mutu, perencanaan mutu, pelaksanaan, evaluasi Kualitas, 3) Peran Kepala Sekolah Tim Penjamin Mutu dalam menerapkan manajemen yakni, sebagai pelaksana, perencana, seorang ahli, mengawasi, mewakili kelompok, pemberi ganjaran/pujian, hukuman. Sedangkan Tim Penjamin Mutu merencanakan, melaksanakan, mengendalikan, mengembangkan SPMIDikdasmen, menyusun dokumen SPMI-Dikdasmen. Disimpulkan bahwa Kondisi Mutu Pendidkan sudah baik, Langkah-langkah penerapan majanemen sudah dilaksanakan, Peran Kepala Sekolah Tim Penjamin Mutu Pendidikan dalam melaksanakan manajemen di SDN 1 Lejang, Kabupaten Pangkep, sudah dilaksanakan dengan baik sesuai dengan tugas dan fungsinya.
\end{abstract}

Kata Kunci: Peran Kepala Sekolah, Penjamin Mutu

\section{THE ROLE OF THE PRINCIPAL AND THE SCHOOL QUALITY ASSURANCE TEAM IN IMPLEMENTING QUALITY MANAGEMENT IN SDN 1 LEJANG, PANGKEP REGENCY}

\begin{abstract}
This study aims to describe 1) the condition of the quality of education, 2) the steps for implementing management, 3) the role of the principal of the Quality Assurance Team in implementing management at SDN 1 Lejang, Pangkep Regency. This type of research is descriptive qualitative. Phenomonology research design. Data collection techniques through observation, interviews, documentation. Data analysis techniques using data reduction, data presentation, drawing conclusions. The results of the study show that 1) the quality of education is good, but the facilities and infrastructure are still lacking, 2) the steps for implementing management are quality determination, quality mapping, quality planning, implementation, quality evaluation, 3) the role of the principal of the quality assurance team. In implementing management, namely, as an executor, planner, an expert, supervising, representing
\end{abstract}


the group, giving rewards/praises, punishments. Meanwhile, the Quality Assurance Team plans, implements, controls, develops SPMI-Dikdasmen, prepares SPMI-Dikdasmen documents. It is concluded that the quality of education is good, the steps for implementing management have been carried out, the role of the Principal of the Education Quality Assurance Team in carrying out management at SDN 1 Lejang, Pangkep Regency, has been carried out properly in accordance with its duties and functions.

Keyword: The Role of the Principal, Quality Assurance

\section{Pendahuluan}

Menurut Peraturan Pemerintah Republik Indonesia Nomor 19 Tahun 2005, setiap satuan pendidikan, baik formal maupun informal, wajib menjamin mutu pendidikan. Penjaminan mutu pendidikan. Hal ini dimaksudkan untuk memenuhi Standar Nasional Pendidikan (SNP). Menurut Permendikbud Nomor 28 Tahun 2016, tentang Sistem Penjaminan Mutu Pendidikan, "Sistem Penjaminan Mutu Internal Pendidikan Dasar dan Menengah. SPMI Dikdasmen, kesatuan unsur yang terdiri dari kebijakan dan proses terkait untuk menjamin penjaminan mutu pendidikan, yang dilaksanakan oleh setiap satuan pendidikan dasar dan menengah untuk menjamin terwujudnya pendidikan bermutu yang memenuhi atau melampaui Standar Nasional Pendidikan (Rois, 2017).

Peran kepala sekolah dalam kaitannya dengan SPMI di dunia yang ideal sejauh ia menjalankan kepemimpinan. Ini sesuai dengan kemajuan yang akan dibuat sekolah jika pemimpin yang tepat bertanggung jawab. Fakta menunjukkan bahwa sekolah biasa dapat dengan cepat menjadi sekolah berkualitas di tangan pemimpin yang hebat. Pemimpin yang berkualitas dapat membawa terobosan atau inovasi yang mendorong sekolah yang dipimpinnya ke tingkat pencapaian yang baru. Seorang pemimpin yang hebat juga dapat meningkatkan moral orang-orang yang dipimpinnya, sehingga tidak ada tekanan untuk bekerja lebih keras dari yang diperlukan untuk mencapai hasil terbaik. Kepala sekolah diharapkan menjadi pemimpin yang ideal dalam bidang pendidikan agar lembaga yang dipimpinnya dapat maju, menerapkan manajemen mutu, dan menghasilkan siswa yang berkualitas sebagai output. Hal ini dimungkinkan dengan kepala sekolah yang sadar akan tanggung jawabnya (Gunawan, 2016).

Sementara itu, tim penjaminan mutu sekolah membantu kepala sekolah dalam perannya memastikan mutu pendidikan sekolah setiap hari. Tim penjaminan mutu di sekolah membawahi delapan (delapan) standar yang harus dipenuhi agar sekolah memenuhi standar nasional pendidikan. Penting untuk mengkaji peran kepala sekolah dan tim penjaminan mutu pendidikan untuk memperoleh informasi yang akurat tentang upaya unsur penjaminan mutu pendidikan, sehingga kegiatan yang dilakukan konsisten dengan hasil yang diharapkan. pendidikan untuk terus meningkatkan mutu pendidikan sehingga mutu pendidikan berangsur-angsur membaik dari waktu ke waktu, hingga standar yang ditetapkan terpenuhi atau bahkan terlampaui (Sutiara, 2021).

Temuan (Muflihah, 2019) peran kepala sekolah dalam meningkatkan kualitas manajemen pendidikan di madrasah ibtidaiyah. Temuan menunjukkan bahwa kepala sekolah di MI NU Raudlatut Tholibin telah melakukan berbagai upaya dan berperan dalam meningkatkan manajemen mutu pendidikan. Bagi guru, siswa, sarana prasarana, dan pendukung sekolah lainnya, telah dilakukan upaya untuk mengisi berbagai peran penting dalam kepemimpinan dan pengelolaan madrasah. Kesimpulan penelitian ini adalah peran kepala sekolah dalam meningkatkan manajemen mutu pendidikan sangat penting, dan peran kepala sekolah telah dimainkan oleh pendidik, manajer, administrator, supervisor, pemimpin, inovator, dan motivator.

Selain fenomena tersebut, penulis ingin meneliti "Peranan Kepala Tim Penjaminan Mutu dalam Pelaksanaan Manajemen di SDN 1 Lejang Kabupaten Pangkep". Tujuan penelitian ini adalah untuk mendeskripsikan keadaan mutu pendidikan di SDN 1 Lejang Kabupaten Pangkep, serta langkah-langkah mendeskripsikan penerapan manajemen mutu di SDN 1 Lejang, Kabupaten Pangkep dan peran Kepala Sekolah Tim Penjaminan Mutu dalam penyelenggaraan pendidikan manajemen di SDN 1 Lejang, Kabupaten Pangkep. 


\section{Metode Penelitian}

Jenis penelitian ini menggunakan metode Deskriptif Kualitatif. Desain penelitian Fenomenologis, yaitu cara berpikir yang menekankan atau berfokus pada pengalaman subjektif manusia dan interpretasi dunia yang dihadapi. Sumber data penelitian yakni (1) satu kepala sekolah dan (7) tujuh guru di SDN 1 Lejang, Kabupaten Pangkep, sebanyak (8) delapan orang. Teknik pengumpulan data dengan Observasi, Wawancara, dan Dokumentasi. Teknik analisis data mengunakan Reduksi data, Penyajian data, dan Penarikan kesimpulan. Wawancara dilakukan dengan mengajukan pertanyaan berikut:

- Bagimanakah kondisi Mutu Pendidikan di SDN 1 Lejang, Kabupaten Pangkep.

- Bagimanakah langkah-langkah Penerapan Manajemen di SDN 1 Lejang, Kabupaten Pangkep.

- Bagimanakah peran Kepala Sekolah Tim Penjamin Mutu Sekolah dalam Menerapkan Manajemen di SDN 1 Lejang, Kabupaten Pangkep.

\section{Hasil dan Pembahasan}

Wawancara dengan informan dilakukan sebagai bagian dari proses penelitian (Gambar 1).

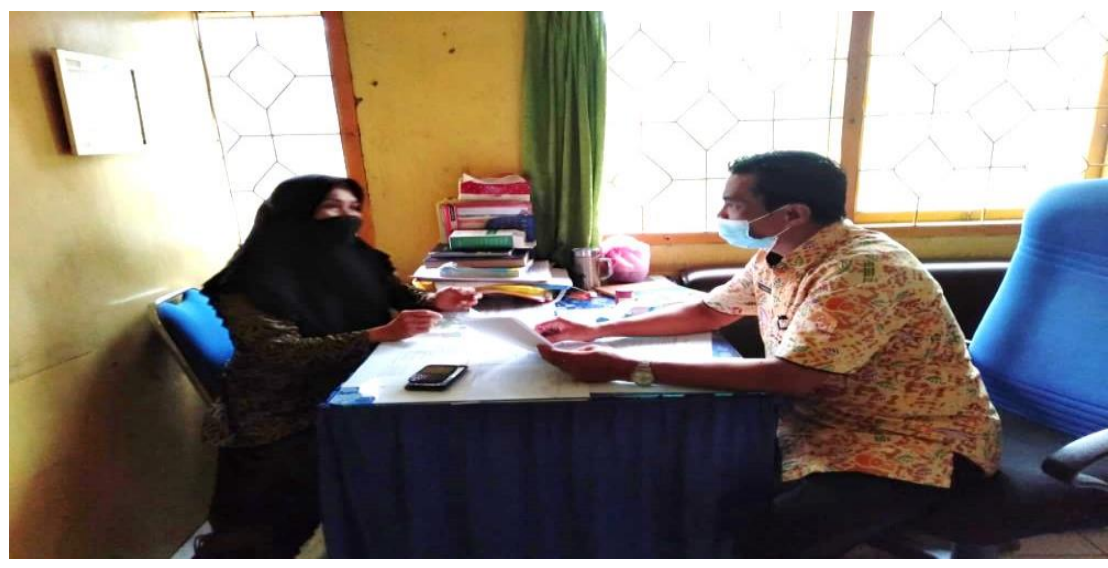

Gambar I. Wawancara terhadap salah satu informan

Kondisi Mutu Pendidikan di SDN 1 Lejang, Kabupaten Pangkep dapat terlihat pada tabel 1 berikut:

Tabel I. Kondisi Mutu Pendidikan di SDN 1 Lejang, Kabupaten Pangkep

\begin{tabular}{ll}
\hline \multicolumn{1}{c}{ Nama } & \multicolumn{1}{c}{ Hasil } \\
\hline Kepala Sekolah (Syh) & $\begin{array}{l}\text { Iya, sudah dilaksanakan namun Sarana dan Prasarana } \\
\text { yang minim untuk digunakan secara optimal. }\end{array}$ \\
Guru (Rkh) & $\begin{array}{l}\text { Kepala sekolah sudah berupaya maksimal namun hasilnya } \\
\text { masih standar 4, semoga nanti bisa meningkat. }\end{array}$ \\
\hline
\end{tabular}

Langkah-langkah Penerapan Manajemen di SDN 1 Lejang, Kabupaten Pangkep dapat terlihat pada tabel 2 berikut:

Tabel II. Langkah-langkah Penerapan Manajemen di SDN 1 Lejang Kabupaten Pangkep

\begin{tabular}{cl}
\hline Nama & \multicolumn{1}{c}{ Hasil } \\
\hline Kepala Sekolah (Syh) & Menyatakan bahwa ada 5 (lima) langkah manajemen \\
& mutu yang dijalankan yakni: 1) manajemen penetapan \\
& mutu, 2) manajemen pemetaan mutu sekolah, 3) \\
& manajemen perencanaan mutu sekolah, 4) manajemen \\
\hline
\end{tabular}




\begin{tabular}{ll}
\hline & inplementasi pemenuhan mutu sekolah dan langkah, 5) \\
& manajemen Mutu Pendidikan (Evaluasi Mutu Sekolah). \\
& Menyatakan bahwa manajemen kepala adalah \\
Guru (Rkh) & mengelola siklus mutu yang ada di menurut Badan \\
& standar Nasional Pendidikan yakni. Menetapkan, \\
& merencanakan, melaksanakan, dan menvaluasi kegiatan.
\end{tabular}

Peran Kepala Sekolah dalam Menerapkan Manajemen di SDN 1 Lejang, Kabupaten Pangkep dapat terlihat pada tabel 3 berikut:

Tabel III. Peran Kepala Sekolah dalam Menerapkan Manajemen di SDN 1 Lejang Kabupaten Pangkep

\begin{tabular}{cl}
\hline Nama & \multicolumn{1}{c}{ Hasil } \\
\hline Kepala sekolah (Syh) & Peran kepala sekolah, dinyatakan. 1) Sebagai \\
& perencana, 2) sebagai pelaksana, 3) sebagai ahli, dan 4) \\
& sebagai pengawas hubungan anggota kelompok \\
& (pengendali hubungan internal), 5) Mewakili kelompok \\
& (group representative), 6) Menjaga anggota kelompok \\
& 7) Sebagai pencipta/idealis (idiolog), 8) sebagai \\
& pemberi pujian dan hukuman, dan 9) sebagai wasit dan \\
& mediator (arbiter dan moderator). \\
\hline
\end{tabular}

Peran Tim Penjamin Mutu Sekolah dalam Menerapkan Manajemen di SDN 1 Lejang, Kabupaten Pangkep dapat dilihat pada tabel 4 berikut:

Tabel IV. Peran Tim Penjamin Mutu Sekolah dalam Menerapkan Manajemen di SDN 1 Lejang Kabupaten Pangkep

\begin{tabular}{|c|c|}
\hline Nama & Hasil \\
\hline Kepala sekolah (Syh) & $\begin{array}{l}\text { Tim Penjamin Mutu Pendidikan Sekolah (TPMPS) Sekolah, } \\
\text { terdiria dari tim: 1)Tim Pengembang dan 2) Tim Evaluasi. }\end{array}$ \\
\hline Guru (Drh) & $\begin{array}{l}\text { Menyatakan bahwa terdiri dari dua tim yaitu } \\
\text { pengembang dan evaluasi atau sering disebut tim monev. }\end{array}$ \\
\hline Guru (Nfr) & $\begin{array}{l}\text { Menyatakan bahwa dipilih dari guru yang sudah senior } \\
\text { membuat perencanaan peningkatan mutu yang } \\
\text { dituangkan dalam rencana kerja sekolah. }\end{array}$ \\
\hline & $\begin{array}{l}\text { Menyatakan bahwa memberikan rekomendasi strategi } \\
\text { peningkatan mutu kepada kepala satuan pendidikan } \\
\text { berdasarkan hasil monitoring dan evaluasi. Tim Pembina }\end{array}$ \\
\hline Guru (SIm) & $\begin{array}{l}\text { Sekolah dan Tim Audit Internal membentuk Tim } \\
\text { Penjaminan Mutu Pendidikan Sekolah (TPMPS). Tim } \\
\text { Monitoring dan Evaluasi bertugas melakukan } \\
\text { pengendalian, evaluasi, dan audit, sedangkan Tim } \\
\text { Pengembang bertugas memetakan, merencanakan, dan } \\
\text { melaksanakan pemenuhan mutu. }\end{array}$ \\
\hline
\end{tabular}


Berkaitan dengan Peran Kepala Sekolah Tim Penjamin Mutu dalam menerapkan manajemen di SDN 1 Lejang, Kabupaten Pangkep, Menurut (Ekawaty, 2018) kemampuan kepala sekolah untuk mengantisipasi perubahan lingkungan eksternal sangat penting bagi kelangsungan dan keberhasilan organisasi. Organisasi dalam situasi ini membutuhkan pemimpin yang efektif untuk melakukan manajemen guna mengelola perubahan yang sedang berlangsung. Tantangan bagi seorang pengelola pendidikan, seperti kepala sekolah, adalah menjadi penggerak atau pionir dalam memodernisasi lembaga pendidikan. (Fitrah, 2017) juga mengklaim bahwa profesionalisme kepala sekolah ini memungkinkan untuk pengembangan profesional. Tenaga kependidikan mudah dikelola karena kepala sekolah memahami kebutuhan sekolah yang dipimpinnya, sehingga kompetensi guru tidak sebatas kompetensi yang dimilikinya sebelumnya, tetapi tumbuh dan berkembang sehingga menghasilkan profesionalisme guru. Peran kepala sekolah sangat penting untuk keberhasilan formal lembaga pendidikan: Menemukan seorang pemimpin, di sisi lain, adalah masalah tidak hanya dalam bisnis, tetapi juga dalam pendidikan. Lima kemampuan dasar berikut ini diperlukan seorang kepala sekolah. Untuk memulai, pelajari tentang visi organisasi dan kembangkan visi kerja yang jelas. Kedua, Anda harus mampu dan mau berusaha keras. Ketiga, bekerja dengan bawahan dengan tekun dan konsisten. Keempat, menjaga sikap rendah hati sambil memberikan layanan yang luar biasa. Menjaga disiplin kerja yang tinggi.

Lanjut (Arjunaita et al., 2020) menegaskan bahwa kualitas kepala sekolah terkait dengan berbagai aspek kehidupan sekolah, antara lain disiplin sekolah, iklim budaya sekolah, dan berkurangnya perilaku menyimpang guru dan siswa. Kondisi yang baik, nyaman, tentram, dan sehat akan dihasilkan dari sekolah yang disiplin secara konsisten. Istilah disiplin merupakan adaptasi dari bahasa Inggris, khususnya "discipline", yang berarti upaya pembinaan dan pengendalian pola pikir dan budi pekerti agar tercapai ketaatan dan ketaatan pada perilaku tertib dan tertib.

Menurut (Puspa et al., 2021) Sistem Penjaminan Mutu Pendidikan (SPMP) merupakan komponen penting yang tidak dapat dipisahkan dari sistem peningkatan mutu, yang terdiri dari dua kegiatan besar: pertama, peningkatan mutu berdasarkan sasaran mutu sekolah. ; dan kedua, peningkatan mutu berdasarkan sasaran mutu sekolah. Kedua, kualitas kinerja dinilai untuk menentukan tingkat kesesuaian standar dengan tujuan program. Lembaga pendidikan akan terbiasa dengan budaya peningkatan mutu jika sistem ini diterapkan dengan baik. Pengertian Penjaminan Mutu Pendidikan, berdasarkan uraian dan pendapat di atas, adalah suatu mekanisme yang sistematis, terpadu, dan berkesinambungan untuk memastikan bahwa seluruh proses penyelenggaraan pendidikan telah memenuhi standar mutu.

Menurut (Nur, 2007) keberadaan pengawas di bidang pendidikan telah lama dikenal, dan di kalangan generasi tua, istilah "PS" atau pengawas dikenal antara lain. Karena kelompok profesi ini dipercayakan, kedudukan lembaga ini menjadi semakin penting, terutama sejak diterbitkannya Peraturan Pemerintah Nomor 19 Tahun 2005 tentang Standar Nasional Pendidikan dan Peraturan Menteri Pendidikan Nasional Nomor 12 Tahun 2007 tentang Standar Pengawasan. Sekolah/Madrasah (di atas 60 persen). Sedangkan evaluasi akademik dan pendidikan masih rendah untuk kompetensi yang paling erat kaitannya dengan pengungkit utama, khususnya kompetensi supervisor, masing-masing sebesar 56 dan 50 persen. Selain itu, inkonsistensi dalam perekrutan supervisor (prinsip) dapat menjadi faktor dalam situasi ini. Pengawas dapat diangkat dari mantan birokrat pendidikan yang hanya ingin memperpanjang masa pensiunnya sebagai pegawai negeri sipil, atau dari mantan kepala sekolah yang "belum siap" menjadi guru setelah masa jabatannya berakhir, atau jumlah pengawas sekolah yang diangkat tidak mencukupi. dari profesor (yang belum pernah menjadi kepala sekolah, sehingga sulit untuk mengembangkan kepala sekolah).

Menurut (Anwar, 2018) menyatakan bahwa Sebagaimana tertuang dalam Undang-Undang Nomor 20 Tahun 2003 tentang Sistem Pendidikan Nasional, mutu pendidikan berkaitan dengan tercapai atau tidaknya tujuan pendidikan di tingkat nasional. Selanjutnya, jika pendidikan memenuhi Standar Nasional Pendidikan, dikatakan bermutu tinggi. Standar Nasional Pendidikan yang merupakan standar minimal pendidikan harus dipenuhi dalam rangka peningkatan mutu pendidikan, termasuk madrasah. Upaya ini dilakukan karena pendidikan berkualitas tinggi memberikan harapan kepada siswa di seluruh negeri. Pendidikan diharapkan dapat menghasilkan manusia Indonesia seutuhnya, sesuai dengan peraturan perundang-undangan yang berlaku. Dalam sistem pendidikan kita, pendidikan yang berkualitas harus disampaikan melalui berbagai jalur, jenis, dan jenjang, termasuk pendidikan madrasah. Jika pemerintah, masyarakat, dan keluarga semua 
bekerja sama, pendidikan yang berkualitas dapat dilaksanakan. Di semua jenjang dan jenjang pendidikan, semua warga negara Indonesia harus memiliki akses pendidikan yang bermutu tinggi.

\section{Kesimpulan}

Kondisi manajemen mutu pendidikan di SDN 1 Lejang Kabupaten Pangkep sudah berada pada level 3 SNP yang ditetapkan oleh Badan Akreditasi Nasional Sekolah Dasar ditetapkan sebesar 7,00. Penetapan, pemetaan, perencanaan, pelaksanaan, dan evaluasi. Langkah-langkah penerapan manajemen mutu pendidikan dilakukan setiap tahun. Peran Kepala Sekolah Tim Penjamin Mutu dalam menerapkan manajemen mutu pendidikan di SDN 1 Lejang Kabupaten Pangkep yakni sebagai pelaksana, perencana, ahli, mengawasi kelompok, mewakili kelompok, memberikan penghargaan/pujian dan hukuman. Sedangkan Tim Penjamin Mutu Sekolah bertanggung, merencanakan, melaksanakan, mengendalikan, mengembangkan SPMI-Dikdasmen, menyusun dokumen SPMI-Dikdasmen, membuat rencana peningkatan mutu yang dituangkan dalam rencana kerja sekolah. Dapat disimpulkan bahwa Kondisi Mutu Pendidikan sudah baik, Langkah-langkah sudah dilaksanakan dengan baik, Peran Kepala Sekolah Tim Penjamin Mutu sudah melaksanakan tanggungjawabnya dengan baik sesuai tugas dan fungsi Kepala Sekolah maupun Tim Penjam Mutu tersebut.

\section{Referensi}

Anwar, K. (2018). PERAN SISTEM PENJAMINAN MUTU PENDIDIKAN DALAM MENINGKATKAN MUTU PENDIDIKAN DI MADRASAH. TA'DIBUNA: Jurnal Pendidikan Agama Islam, 1(1), 41. https://doi.org/10.30659/jpai.1.1.41-56

Arjunaita, A., Fitria, H., \& Rohana, R. (2020). Peran Kepala Sekolah dalam Menerapkan Disiplin Kerja Guru. Jurnal Pendidikan Tambusai, 4(2), 1667-1675. https://doi.org/10.31004/jptam.v4i2.631

Ekawaty, A. E. (2018). PELAKSANAAN SUPERVISI MANAJERIAL OLEH PENGAWAS SEKOLAH DALAM MENINGKATKAN MUTU PENDIDIKAN DI SDN 3 PERCONTOHAN PEUSANGAN KABUPATEN BIREUEN. Jurnal Magister Administrasi Pendidikan, 6(3), 183-191.

Fitrah, M. (2017). PERAN KEPALA SEKOLAH DALAM MENINGKATKAN MUTU PENDIDIKAN. Jurnal Penjaminan Mutu, 3(1), 31. https://doi.org/10.25078/jpm.v3i1.90

Gunawan, I. (2016). Merevitalisasi Kepemimpinan Pancasila dalam Bidang Pendidikan. Universitas Negeri Malang, Malang, 12(2), 67-68. http://ap.fip.um.ac.id/wp-content/uploads/2016/03/5-ImamGunawan.pdf

Muflihah, A. (2019). Peran kepala sekolah dalam meningkatkan manajemen mutu pendidikan di madrasah ibtidaiyah. Journal Quality, 7(2), 48-63.

Nur, T. (2007). OPTIMALISASI PERAN PENGAWAS SEKOLAH DAN FASILITASI OLEH LEMBAGA PENJAMINAN MUTU PENDIDIKAN. Jurnal Lambaga Penjamin Mutu, 1(2), 245. http://digilib.unila.ac.id/11478/16/16. BAB II.pdf

Puspa, E. M., Sutanto, A., \& Aminin, S. (2021). EVALUASI SISTEM PENJAMINAN MUTU INTERNAL (SPMI) PADA SEKOLAH MODEL LAMPUNG TIMUR. POACE: Jurnal Program Studi Adminitrasi Pendidikan, 1(1), 20-32. https://doi.org/10.24127/poace.v1i1.610

Rois, M. (2017). Kepemimpinan Kepala Sekolah Dalam Meningkatkan Kompetensi Guru. Edudeena, 1(2), 18. https://doi.org/10.30762/ed.v1i2.449

Sutiara, A. (2021). Manajerial Kepala Sekolah Dalam Meningkatkan Mutu Pendidik Di Sdn 4 Margadadi. In Prosiding dan Web Seminar (Webinar). 